\title{
Mutations in the Basal Core Promoter and Precore/Core Regions of Hepatitis B Virus in Patients Co-Infected With Human Immunodeficiency Virus
}

\author{
Ahmad Hosseinzadeh Adli \\ (MSc) \\ Department of Microbiology, \\ Golestan University of Medical \\ Sciences, Gorgan, Iran \\ Chiman Karami (MSc) \\ Department of Microbiology, \\ Golestan University of Medical \\ Sciences, Gorgan, Iran \\ Sareh Zhand (PhD) \\ Department of Biotechology, \\ Golestan University of Medical \\ Sciences, Gorgan, Iran \\ Reza Talei (PhD) \\ Department of Microbiology, \\ Lorestan University of Medical \\ Sciences, Khorram Abad, Iran \\ Abdolvahab Moradi (PhD) \\ Gastroenterology and Hepatology \\ Research Center, Golestan \\ University of Medical Sciences, \\ Gorgan, Iran
}

Corresponding author: Abdolvahab Moradi

Email: abmoradi@yahoo.com

Address: Research Center, Golestan University of Medical Sciences, Gorgan, Iran

Received : 09 Aug 2015

Revised: 19 Sep 2015

Accepted: 13 Nov 2015
ABSTRACT

Background and objectives: Globally, about one third of the population has been infected with Hepatitis B virus (HBV) and more than 400 million people have become chronically infected. Nearly, 20-25\% of all carriers develop serious liver diseases such as cirrhosis, chronic hepatitis and hepatocellular carcinoma ( $\mathrm{HCC}$ ). According to the World Health Organization, HBV infection causes more than one million deaths every year. Coinfection with Human Immunodeficiency virus (HIV) and HBV is common, since both viruses have the same routes of transmission. Approximately 10 -15\% of HIV-infected individuals develop chronic hepatitis B. The risk of liver diseases-related deaths is also higher in the coinfected patients. According to previous studies, mutation of the pre-core $(\mathrm{PC})$ and basalcore promoter (BCP) regions may play an important role in development of HBV-related HCC and severe liver disease. The aim of this study was to investigate mutations in the BCP, PC and core regions of $\mathrm{HBV}$ in HIV-positive patients.

Methods: INA was extracted using commercial kits to determine the BCP, PC/core mutations in $124 \mathrm{HIV} / \mathrm{HBV}$ co-infected patients (32.4\% female and $67.6 \%$ male). P0lymerase chain reaction (PCR) was performed using specific primers. The positive PCR products were subjected to automated sequencing. Then, nucleotide sequences were aligned with the standard hepatitis B sequence [Gene bank, accession number: AB033559] for mutation detection and analysis.

Results: In this study, three patients (0.1\%) were HBeAg-positive and all of them were HBsAg-positive. The mean of CD4 cell count was 120 cells/mL. The mean age of the patients was 36.16 years. The important pathological mutations in HBV patients including 1752A (73\%), 1773C (70.3\%), 1753C (10.0\%), 1896A (8.1\%) and 1762T/1764A (2.7\%) were detected in this study.

Conclusion: Identification of mutations in co-infected patients is of greater importance compared to mono-infected patients, because it can be useful for prediction of HCC-related mutations. Co-infection with HIV has important effects on the natural history of HBV infection, and creates different mutational patterns compared to mono-infected patients.

Keywords: HBV, HIV, Mutation. 


\section{INTRODUCTION}

Hepatitis B virus (HBV) infection is an important health problem in the world._About more than one third of the world's population has been infected with HBV. While $2-10 \%$ of the world's population are chronic carriers of $\mathrm{HBV}$, nearly $25 \%$ of them develop serious liver diseases such as cirrhosis, chronic hepatitis and hepatocellular carcinoma (HCC). Hepatitis B infection leads to more than one million deaths every year (1-3). Polymerase chain reactions (PCR)-based assays and genome sequence analysis have shown remarkable genetic variability in $\mathrm{HBV}$. Currently, 10 genotypes (A-J) and several sub-genotypes have been identified, which are scattered across different geographical regions (4). Although Iran is considered a low endemicity country, the prevalence of HBV is increasing in the country. The co-infection with human immunodeficiency virus (HIV) is another important challenge in the healthcare system (5). Co-infection with HIV and HBV is common, since both viruses are usually transmitted through blood-to-blood contact and sexual contact. Approximately $10-15 \%$ of HIV-infected individuals are chronically infected with hepatitis B. In highly endemic areas like Africa and Asia, the prevalence of HBV is even higher (6). It is well demonstrated that HIV infection can accelerate $\mathrm{HBV}$-associated liver diseases, such as the progression of cirrhosis in co-infected individuals (4). The risk of death caused by liver disease in HIV-HBV co-infected patients is 14 times higher than in mono-infected patients (7). Different HBV genotypes may have distinct impacts on progression of acquired immune deficiency syndrome. Increasing evidence suggests that HBV genotype is an important factor in determining HBV disease progression and response to antiviral treatment. In addition, certain mutations that emerge under medical pressure (vaccine or antiviral therapy) made the management of HBV infection more difficult (7). Mutations in the pre-core (PC)/core promoter are not HBV genotype restricted and there is limited information available on the association between HIV infection and HBV mutations in co-infected patients. The route of transmission and prevalence of $\mathrm{HBV}$ in HIV-positive patients are different. The highest incidents of $\mathrm{HBV}$ transmission in HIV co-infected individuals are observed in homosexual men followed by intravenous drug users, especially in $\operatorname{Iran}(8,9)$. The rate of $\mathrm{HBV}$ virion production (up to $10^{11} /$ day) is higher than HIV and approximately 10 times higher than other DNA viruses. The HBV reverse transcriptase does not have proofreading activity, and with enormous daily virion production, errors occur during replication. The error rate of the HBV pol has been estimated as $10^{-7}$ per nucleotide per day. Thus, approximately $10^{14}$ nucleotides are replicated daily with potentially $10^{7}$ base pairing errors (10). The core promoter (CP, nt1575-1849) of the viral genome plays a significant role in HBV replication as it directs initiation of transcription for the synthesis of both the PC and pre-genomic (pg) RNAs. The $\mathrm{CP}$ consists of the basal core promoter (BCP, nt 1743-1849) and the upper regulatory region (nt 1613-1742). The BCP has both positive and negative regulatory elements that modulate promoter activity (10). It is sufficient for precise initiation of both PC mRNA and pg RNA transcription in vivo. BCP contains a major nuclear binding site, which is recognized by different members of the nuclear receptors superfamily (including PPAR $\alpha-R X R \alpha$ heterodimer, HNF4) and a series of transcription factors (such as C/EBP) to regulate the transcription of the $\mathrm{PC}$ and core RNAs. The CP overlaps with the 3'-end of the $X$ ORF (nucleotide 1374-1836) that affect mutations in this region. The 5'-end of the PC region also contains cis-acting elements, and its transcription regulation is controlled by cellular and viral factors. This regulatory region exhibits high sequence conservation but when variations occur, they may contribute to the persistence of $\mathrm{HBV}$ within the host, leading to chronic infection and cirrhosis. Different biological functions of the PC and pg RNA, and differential regulation of BCP may affect HBV replication and pathogenesis (1113). $\mathrm{G}$ to $\mathrm{A}$ change at nucleotide 1896 is the most frequently observed mutation in the PC region, which results in a stop codon and ultimately leading to premature termination of the $\mathrm{PC} /$ core protein (precursor of $\mathrm{HBeAg}$ ). This mutation is located within the epsilon $(\varepsilon)$ structure, a highly conserved stem-loop that is crucial for initiation of encapsidation within the viral replication cycle. However, this mutation pattern in co-infected patients is slightly different and less frequent $(13,14)$. 
Isolates with transversion at $\mathrm{A} 1762 \mathrm{~T}$ together with G1764A mutations in the BCP are often present in hepatitis $\mathrm{B}$ carriers with chronic hepatitis, fulminant hepatic failure (FHF) and HCC patients but less frequent in inactive carriers and immune suppressed patients. The 1762 and 1764 mutations reduce transcription of the PC mRNA by interfering binding of transcription factors, which in turn downregulates $\mathrm{HBeAg}$ synthesis. Some studies have shown that genomic mutations at positions 1727G, 1741C, 1761C, 1757A /1764T /1766G, 1773T, 1773T /1775G and 1909C are associated with $\mathrm{HCC}$ in $\mathrm{HBV}$-infected patients (15-19). Several studies have reported an association between $\mathrm{CP}$ mutations and increased risk of liver inflammation, cirrhosis (20) and HCC (21). Some studies have reported an association between PC mutations and fulminant hepatitis (22-24). To our knowledge, there are limited reports on HBV $\mathrm{BCP}, \mathrm{PC} /$ core mutations in patients coinfected with HIV in Iran. The current study investigated the mutational patterns of $\mathrm{HBV}$ in HIV-HBV co-infected patients.

\section{MATERIAL AND METHODS}

A cross-sectional study was performed to identify patients with HIV and HBV coinfection. Blood samples were collected from 124 patients with confirmed HIV/HBV infection who were referred to HIV Prevention Centers in cities of Kermanshah, Khorramabad, Tehran and Shiraz. Serum samples were collected to identify and confirm hepatitis B by serological testing using HBV serological markers, enzyme immunoassay kits (HBsAg, anti-HBc, and $\mathrm{HBeAg}$ ) (Dade Behring Inc., Delaware, USA) and virological analysis. Medical records and demographic data including gender, age, CD4 count and probable route of HIV transmission were collected. The most common route of HIV transmission $(59.40 \%)$ was via intravenous drug use along with risky sexual behavior.

Two hundred $\mu$ of serum were used for HBVDNA extraction using commercial high pure viral nucleic acid kits (Roche, Hamburg, Germany), according to manufacturer's instructions. The DNA was amplified by polymerase chain reaction (PCR) using the following pair of primers (GeNet Bio, Korea): Forward 5'ACCTTGAGGCATACTTCAAA- 3' Reverse 5'-CAGAATAGCTTGCCTGAGTGC-3'
The length of amplicon was $390 \mathrm{bp}$. Briefly, $100 \mathrm{ng}$ of the extracted DNA was added to an amplification mixture containing 1X PCR buffer, $1.5 \mathrm{Mm} \mathrm{MgCl}_{2}, 0.15 \mathrm{Mm}$ dNTP mix , $2.5 \mathrm{U}$ Taq DNA polymerase (QIAGEN, Hamburg, Germany), $0.2 \mathrm{pmol} / \mu \mathrm{l}$ of each primers and distilled water in a total volume of $50 \mu \mathrm{l}$. Thermal cycling conditions for PCR were as follows: initial denaturation at $95^{\circ} \mathrm{C}$ for $5 \mathrm{~min} ; 35$ amplification cycles (denaturation for $1 \mathrm{~min}$ at $95^{\circ} \mathrm{C}$; annealing of primers for $1 \mathrm{~min}$ at $55^{\circ} \mathrm{C}$; extension for $2 \mathrm{~min}$ at $72^{\circ} \mathrm{C}$ ); and a final extension step for $5 \mathrm{~min}$ at $72^{\circ} \mathrm{C}$.

Direct sequencing of positive PCR products (Macro gene, South Korea) was done to determine the $\mathrm{BCP}$ and $\mathrm{PC} /$ core mutations. The PCR products were compared to the reference sequence (GenBank, Accession number: AB033559) using a BLAST search analysis. The nucleotides were translated into amino acid sequences using the translation tool on NCBI (National Center for Biotechnology Information) website and Gene Runner software to determine amino acid mutations.

The data was analyzed using SPSS software 17.0 (SPSS, Inc., Chicago, IL). P-values < 0.05 were considered as statistically significant. The study was approved by the Research Ethics Committee of Golestan University of Medical Sciences.

\section{RESULTS}

The mean age of patients was 36.16 (43.2\% were $<32$ years). All patients were HBsAg-positive and three $(8.1 \%)$ were HBeAg-positive. The mean of CD4 cell count was $120($ cells $/ \mu \mathrm{L})$. There were 70 point mutations consisting of $42(60 \%)$ missense mutations and $28(40 \%)$ silent mutations, which had no effect on the amino acid sequence. There were $17 \mathrm{BCP}$ mutations at the amino acid level and 25 amino acid changes in the $\mathrm{PC} /$ core region.

Some of the high-level mutations such as 1912T (94.6\%) and 1978A (86.5\%) were silent. The important missenses mutations that altered the amino acid were 2003T/2005A [(100\%) that changes A64S (100\%) amino acid] and 2020A [(86.5\%) that changes D69E amino acid]. The main pathologic mutations in patients were $1762 \mathrm{~T} / 1764 \mathrm{~A}(2.7 \%)$, 1896A $(8.1 \%), 1753 \mathrm{C}(10.8 \%), 1773 \mathrm{~T}(70.3 \%)$ and $1774 \mathrm{~T}(13.5 \%)$. 
Figure 1- The most common amino acid mutations

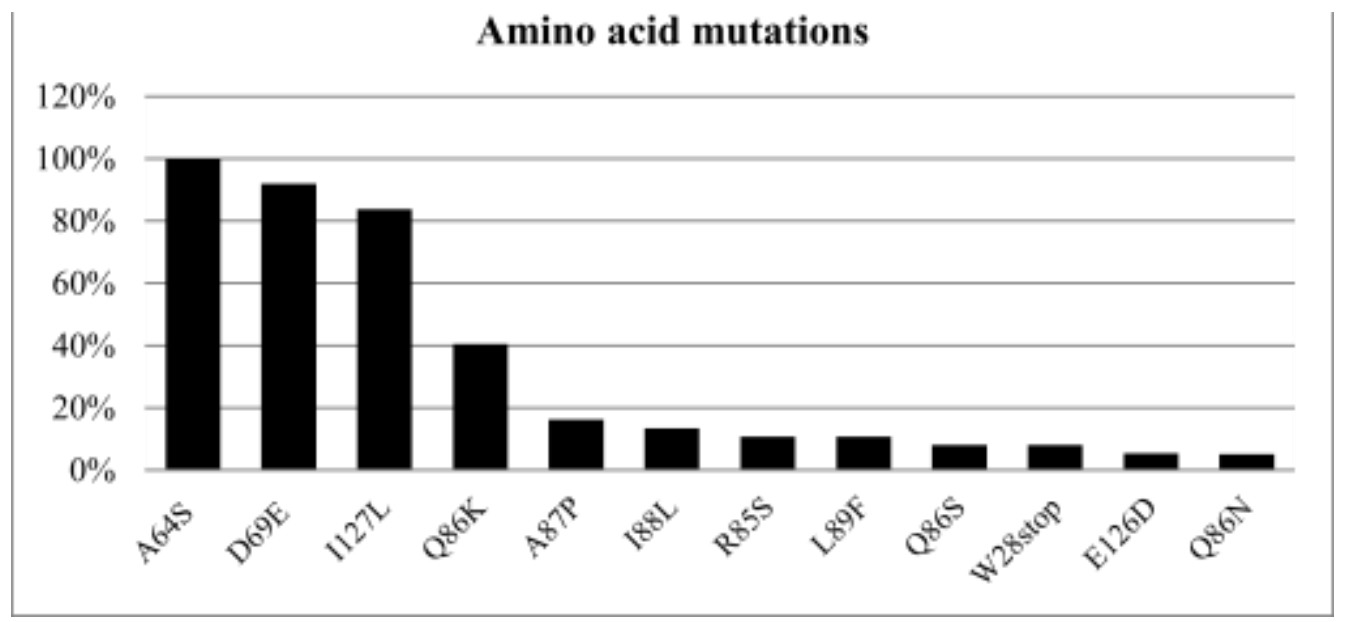

Figure 2- The most common nucleotide mutations

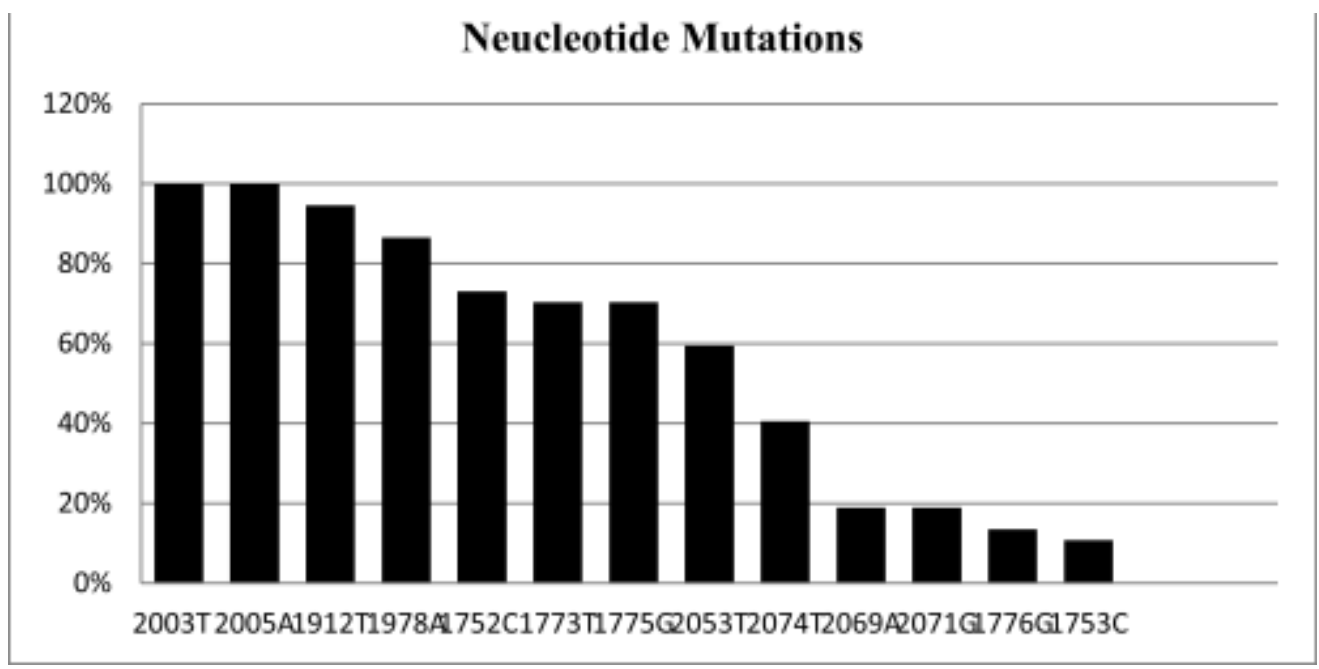

Figure 3- The most common deletion and insertion mutations

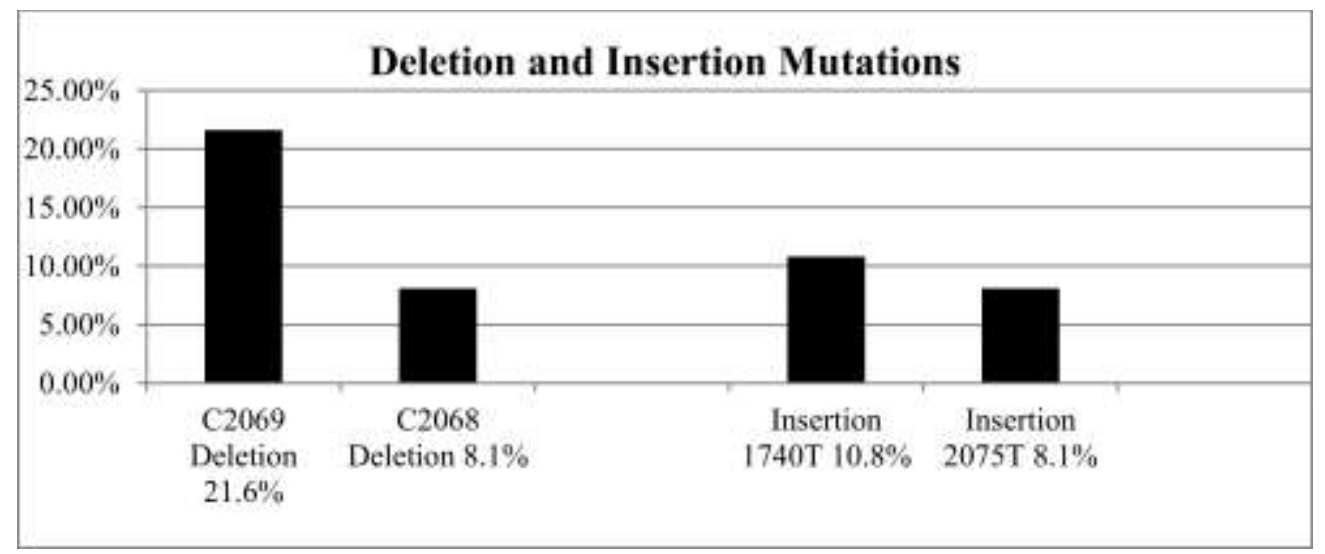


There were 15 insertion and seven deletion mutations. The most common insertion and deletion mutations were observed at nucleotide 1740T (10.8\%) and 2069 (21.6\%), respectively. There was no significant association between the age, gender and $\mathrm{HBeAg}$ of patients, and the patterns of amino acid substitutions.

\section{DISCUSSION}

The co-infection with HIV changes intracellular microenvironment and provides suitable conditions for HBV that leads to more stability and affects mutational patterns. The high rate of mutation in HBV compared to other DNA viruses is due to lack of HBV polymerase proofreading and production of large amounts of virus particles. The patients co-infected with HIV have higher level of hepatitis $\mathrm{B}$ viremia, rapid progression to chronic hepatitis B and increased risk of cirrhosis and HCC compared to mono-infected patients (12). The HBV genotype, CP mutations, and high viral load are viral factors associated with increased risk of HCC. The other hotspot $\mathrm{CP}$ mutations are $1753 \mathrm{~A} / \mathrm{C} / \mathrm{G}$ and 1768A, which are also associated with the increased risk of $\mathrm{HCC}$. BCP mutations are common in HCC patients and there is a high rate of point mutations in this region (particularly dual V131L and $\mathrm{K} 130 \mathrm{M}$ ) among patients with cirrhosis and $\operatorname{HCC}(18,25-27)$. In our study, we identified these mutations in two patients that can be indicator of $\mathrm{HCC}$ progression. Some studies have shown that mutation 1762T/1764A suppresses mRNA transcription and enhances $\mathrm{HBV}$ replication. Although CP mutations may enhance HBV replication(28), several clinical reports have revealed that the presence of $1762 \mathrm{~T} / 1764 \mathrm{~A}$ mutation is not always associated with the high HBV-DNA levels (29). In the study of Chilo L. et al., CD4 counts of patients with HIV/HBV infection were significantly lower than mono-infected patients (30). Another study also demonstrated low amount of CD4 cells in co-infected patients (31). In the present study, the mean number of CD4 cells in patients was $120($ cells $/ \mu \mathrm{L})$. This indicates that HBV infection has caused a substantial decrease in CD4 of co-infected patients. The most common route of HIV transmission is sexual contact, intravenous drug use and perinatal transmission. The most common modes of HIV transmission in Iran are intravenous drug use and risky sexual behaviors $(32,33)$. Similarly, the main modes of transmission in this study were intravenous drug use and history of risky sexual behavior. The high rate of HIV infection in married patients in the present study highlights the need for measures to prevent HIV and HBV infection in family of patients.

Mutation at nucleotide 1762T/1764A increased the level of HBV DNA replication and pg RNA transcription compared to the wild type strain. The serum level of $\mathrm{HBeAg}$ in the $1762 \mathrm{~T} / 1764 \mathrm{~A}$ mutant group is lower than that of the wild type strain. The mutation is located in hepatocyte nuclear factor 4 binding site. A number of liver transcription factors are involved in the regulation of $\mathrm{HBV}$ transcription and replication (34). The mutations at nucleotides 1766T/1768A and 1896A/1899A are associated with high replication levels. Moreover, $1753 \mathrm{C}$ and $1766 \mathrm{~T}$ mutations are related to high replication levels. Apart from the $1753 \mathrm{C}$ mutation that has been observed in HCC patients, other mutations in this study were at low level. HBV replication level in HBV/HIV co-infected patients is lower compared to mono-infected patients. Cassino et al. showed that BCP/PC mutations in $\mathrm{HIV} / \mathrm{HBV}$ patients is lower compared to HBV patients (35), which is consistent with the findings of the present study.

Some studies determined whole genome HBV mutations in co-infected patients. Tangkijvanich et al. found no difference in mutations, age, gender, and $\mathrm{HBeAg}$ and alanine transaminase between co-infected and mono-infected patients. They reported $1762 \mathrm{~T}$, G1764A, 1896A and 1753C mutations in 45.8 $\%, 50 \%, 25 \%$ and $20.8 \%$ of co-infected patients, respectively. The rate of $1762 \mathrm{~T}$, $1764 \mathrm{~A}$ and $1896 \mathrm{~A}$ mutations in co-infected patients in the present study was lower than the values reported by Tangkijvanich et al. This could be due to geographical differences in HBV mutational patterns, since different HBV genotypes are associated with various mutations in the HBV core region(36). Fernando Gallego et al. reported no mutations at nucleotides 1762,1764 and 
1896 in HIV/HBV co-infected patients (37).However, Yousif et al. reported low frequency of these mutations in $\mathrm{HIV} / \mathrm{HBV}$ patients and $88 \%$ frequency rate for $\mathrm{HBeAg}$ negative patients (38), which is in agreement with the findings of the present study. Mutations at nucleotides 1762, 1764, 1812, 1809, 1814-1816 and 1809 affect the production of $\mathrm{HBeAg}$, which is highly immunogenic (39). Since co-infected patients with HIV have reduced immune pressure, a reduction can be seen in the production and secretion of HBeAg. Taffon et al. showed the high frequency of BCP and PC pathobiological mutations in Italian co-infected patients, while several corresponding sites showed amino acid variations. Similar to the present study, the rate of mutations in the mentioned study was not correlated with age and gender. However, high rate of $1762,1764,1766$ and 1809 mutations is related to different geographical distribution of HBV mutations. Different HBV genotypes are associated with mutations in different regions (40-42). Survival of an organism depends on its capacity to cultivate variety. While mutations can cause this variety

\section{REFERENCES}

1. Trépo C, Chan HL, Lok A. Hepatitis B virus infection. The Lancet. 2014;384(9959):2053-63.

2. McMahon BJ. Chronic Hepatitis B Virus Infection. Medical Clinics of North America. 2014; 98(1): 39-54. DOI: 10.1016/j.mena.2013.08.004.

3. El-Serag HB. Epidemiology of Viral Hepatitis and Hepatocellular Carcinoma. Gastroenterology. 2012;142(6):1264-73.e1.

4. Tangkijvanich P, Sa-Nguanmoo P, Avihingsanon A, Ruxrungtham K, Poovorawan K, Poovorawan Y. Characterization of Hepatitis $B$ virus mutations in untreated patients co-infected with HIV and HBV based on complete genome sequencing. J Med Virol. 2013;85(1):16-25. doi: 10.1002/jmv.23430.

5. Alavian SM, Fallahian F, Lankarani KB. The changing epidemiology of viral Hepatitis $B$ in Iran. Journal of Gastrointestinal and Liver Diseases. 2007; 16(4): 403-6.

6. Martín-Carbonero L, Poveda E. Hepatitis B virus and HIV infection. Seminars in liver disease. 2012.

7. Pourkarim MR, Lemey P, Amini-Bavil-Olyaee S, Houspie L, Verbeeck J, Rahman M, et al. Molecular characterization of Hepatitis B virus strains circulating in Belgian patients co-infected with HIV and HBV: Overt and occult infection. J Med Virol. 2011; 83(11): 1876-84. doi: 10.1002/jmv.22174.

8. Nguyen $\mathrm{CH}$, Ishizaki A, Chung PTT, Hoang HT, Nguyen TV, Tanimoto $\mathrm{T}$, et al. Prevalence of $H B V$ infection among different HIV-risk groups in Hai Phong, Vietnam. J Med Virol. 2011; 83(3): 399-404. in viruses, the virus's genome remains unchanged in suitable host environment. Coinfection of patients with HIV provides better conditions for HBV, which results in low rate of mutations in the HBV genome.

It is recommended to conduct a large-scale study in countries with high prevalence of HBV/HIV infections, to evaluate clinical and virological differences between mono-infected and co-infected patients.

\section{CONCLUSION}

Detection of the mutations in the BCP and $\mathrm{PC} /$ core regions of $\mathrm{HBV}$ in co-infected patients could be useful for development of better preventive and therapeutic strategies, and help predict the progression of liver diseases.

\section{ACKNOWLEDGEMENT}

The authors would like to thank the Golestan University of Medical Sciences for financial support.

\section{CONFLICT OF INTEREST}

The authors declare that they have no conflict of interests.

9. Ziaee M, Sharifzadeh G, Namaee MH, Fereidouni M. Prevalence of HIV and Hepatitis B, C, D Infections and Their Associated Risk Factors among Prisoners in Southern Khorasan Province, Iran. Iranian Journal of Public Health. 2014; 43(2): 229-34.

10. Quarleri J. Core promoter: A critical region where the Hepatitis $B$ virus makes decisions. World journal of gastroenterology: WJG. 2014; 20(2): 425-435. doi: $10.3748 /$ wjg.v20.i2.425.

11. Mizuguchi Y, Takizawa T, Uchida E. Host cellular microRNA involvement in the control of Hepatitis B virus gene expression and replication. World journal of hepatology. 2015; 7(4): 696-702. doi: 10.4254/wjh.v7.i4.696.

12. Nordin M, Ingman M, Lindqvist B, Kidd-Ljunggren $\mathrm{K}$. Variability in the precore and core promoter region of the Hepatitis B virus genome. J Med Virol. 2014; 86(3): 437-45. doi: 10.1002/jmv.23839.

13. Tseng T-C, Liu C-J, Yang H-C, Chen C-L, Yang W$\mathrm{T}$, Tsai C-S, et al. Higher proportion of viral basal core promoter mutant increases the risk of liver cirrhosis in Hepatitis B carriers. Gut. 2015; 64(2): 292-302. doi: 10.1136/gutjnl-2014-306977.

14. Kamijo N, Matsumoto A, Umemura T, Shibata S, Ichikawa Y, Kimura T, et al. Mutations of pre-core and basal core promoter before and after Hepatitis $B e$ antigen seroconversion. World journal of gastroenterology: WJG. 2015; 21(2): 541. doi: $10.3748 /$ wjg.v21.i2.541. 
15. Khan A, Al Balwi MA, Tanaka Y, Hajeer A, Sanai FM, Al Abdulkarim I, et al. Novel point mutations and mutational complexes in the enhancer II, core promoter and precore regions of Hepatitis $B$ virus genotype DI associated with hepatocellular carcinoma in Saudi Arabia. International Journal of Cancer. 2013; 133(12): 2864-71. doi: 10.1002/ijc. 28307.

16. Datta S, Ghosh A, Dasgupta D, Ghosh A, Roychoudhury S, Roy G, et al. Novel point and combomutations in the genome of Hepatitis B virus-genotype $D$ : characterization and impact on liver disease progression to hepatocellular carcinoma. PLoS One. 2014 Oct 15;9(10):e110012. doi: 10.1371/journal.pone.0110012.

17. Shen T, Yan X-M. Hepatitis $B$ virus genetic mutations and evolution in liver diseases. World journal of gastroenterology: WJG. 2014; 20(18): 5435.

18. Baqai SF, Proudfoot J, Debbie HY, Mangahas M, Gish RG. High rate of core promoter and precore mutations in patients with chronic hepatitis $B$. Hepatology international. 2015; 9(2): 209-17.

19. Ghaziani T, Sendi H, Shahraz S, Zamor P, Bonkovsky HL. Hepatitis $B$ and liver transplantation: Molecular and clinical features that influence recurrence and outcome. World journal of gastroenterology: WJG. 2014; 20(39): 14142.

20. Lin CL, Liao LY, Wang CS, Chen PJ, Lai MY, Chen DS, et al. Basal core-promoter mutant of Hepatitis $B$ virus and progression of liver disease in Hepatitis $B e$ antigen-negative chronic hepatitis $B$. Liver International. 2005; 25(3): 564-70.

21. Yuen MF, Tanaka Y, Ng IL, Mizokami M, Yuen JH, Wong DH, et al. Hepatic necroinflammation and fibrosis in patients with genotypes $B a$ and $C$, core-promoter and precore mutations. Journal of viral hepatitis. 2005; 12(5): 513-8.

22. Kao JH, Chen PJ, Lai MY, Chen DS. Basal core promoter mutations of Hepatitis $B$ virus increase the risk of hepatocellular carcinoma in Hepatitis $B$ carriers. Gastroenterology. 2003;124(2): 327-34.

23. Yuen M-F, Tanaka Y, Shinkai N, Poon RT, But DY$\mathrm{K}$, Fong DY, et al. Risk for hepatocellular carcinoma with respect to Hepatitis B virus genotypes $B / C$, specific mutations of enhancer II/core promoter/precore regions and HBV DNA levels. Gut. 2008; 57(1): 98-102.

24. Carman WF, Fagan EA, Hadziyannis S, Karayianni $\mathrm{P}$, Tassopoulos NC, Williams R, et al. Association of a precore genomic variant of Hepatitis $B$ virus with fulminant hepatitis. Hepatology. 1991; 14(2): 219-22.

25. Yan J, Yao Z, Hu K, Zhong Y, Li M, Xiong Z, et al. Hepatitis B Virus Core Promoter A1762T/G1764A (TA)/T1753A/T1768A Mutations Contribute to Hepatocarcinogenesis by Deregulating Skp2 and P53. Digestive diseases and sciences. 2015; 60(5): 1315-24.

26. Takahashi K, Ohta Y, Kanai K, Akahane Y, Iwasa Y, Hino $\mathrm{K}$, et al. Clinical implications of mutations $C$-toT1653 and T-to-C/A/G1753 of Hepatitis B virus genotype $C$ genome in chronic liver disease. Archives of virology. 1999; 144(7):1299-308.
27. Hu F, Bi S, Yan H, Shi Y, Sheng J. Associations between Hepatitis B virus basal core promoter/pre-core region mutations and the risk of acute-on-chronic liver failure: a meta-analysis. Virology journal. 2015; 12(1): 1-13. DOI: 10.1186/s12985-015-0313-5.

28. Zhang X, Ding H-G. Key role of Hepatitis B virus mutation in chronic Hepatitis $B$ development to hepatocellular carcinoma. World journal of hepatology. 2015; 7(9): 1282-1286. doi: 10.4254/wjh.v7.i9.1282.

29.Parekh S, Zoulim F, Ahn SH, Tsai A, Li J, Kawai S, et al. Genome replication, virion secretion, and e antigen expression of naturally occurring Hepatitis $B$ virus core promoter mutants. Journal of virology. 2003;77(12):6601-12.

30. Thio CL, Smeaton L, Saulynas M, Hwang H, Saravan S, Kulkarni S, et al. Characterization of HIV$H B V$ co-infection in a multi-national HIV-infected cohort. AIDS (London, England). 2013; 27(2): 191-201. doi: 10.1097/QAD.0b013e32835a9984.

31. Abdi M, Rahbari R, Khatoni Z, Naseri N, Najafi A, Khodadadi I. Serum Adenosine Deaminase (ADA) Activity: A Novel Screening Test to Differentiate HIV Monoinfection From HIV-HBV and HIV-HCV Coinfections. J Clin Lab Anal. 2016; 30(3): 200-3. doi: 10.1002/jcla.21836.

32. Azadmanesh K, Mohraz M, Kazemimanesh M, Aghakhani A, Foroughi M, Banifazl M, et al. Frequency and genotype of human parvovirus B19 among Iranian patients infected with HIV. J Med Virol. 2015; 87(7): 1124-9.

33. Jahanbakhsh F, Hattori J, Matsuda M, Ibe S, Monavari S-HR, Memarnejadian A, et al. Prevalence of transmitted HIV drug resistance in Iran between 2010 and 2011. PLoS One. 2013; 8(4):e61864. doi: 10.1371/journal.pone.0061864.

34. Leng XH, Chen EQ, Du LY, Bai L, Gong DY, Cheng $\mathrm{X}$, et al. Biological characteristics of the A1762T/G1764A mutant strain of Hepatitis B virus in vivo. Molecular Medicine Reports. 2015; 12 (4):5141. DOI: $10.3892 / \mathrm{mmr} .2015 .4072$.

35. Cassino L, Laufer N, Salomon H, Campos R, Quarleri J. Hepatitis B precore/core promoter mutations in isolates from $\mathrm{HBV}$-monoinfected and $\mathrm{HBV}-\mathrm{HIV}$ coinfected patients: A 3-yr prospective study. Journal of Clinical Virology. 2009; 46(4): 354-9.

36. Sunbul M. Hepatitis B virus genotypes: Global distribution and clinical importance. World journal of gastroenterology: WJG. 2014; 20(18): 5427-34.

37. Gallego F, Pisano MB, Torres C, Caeiro L, Wassaf MM, Balangero M, et al. Molecular epidemiology of Hepatitis $B$ virus in Córdoba, Argentina. Journal of Clinical Virology. 2014;61(2):204-10. doi: 10.1016/j.jcv.2014.06.030.

38. Yousif M, Mudawi H, Hussein W, Mukhtar M, Nemeri O, Glebe D, et al. Genotyping and virological characteristics of Hepatitis B virus in HIV-infected individuals in Sudan. International Journal of Infectious Diseases. 2014; 29: 125-32. doi: 10.1016/j.ijid.2014.07.002. 
39. Lapalus M, Laouenan C, Cardoso AC, Estrabaud E, Carvalho-Filho RJ, Zhang Q, et al. Precore/Core promoter variants to predict significant fibrosis in both HBeAg positive and negative chronic hepatitis B. Liver International. 2015; 35(9): 2082-9. doi: 10.1111/liv.12787.

40. Taffon S, Genovese D, Blasi M, Pierotti P, Degli Esposti A, Catone S, et al. HBV whole-genome mutation profile in HIV-1/HBV coinfected patients in a long-term follow-up study. Infection. 2014; 42(4): 675-87. doi: 10.1007/s15010-014-0616-2.
41. Cevik D, Yildiz G, Ozturk M. Common telomerase reverse transcriptase promoter mutations in hepatocellular carcinomas from different geographical locations. World journal of gastroenterology: WJG. 2015; 21(1): 311-17. doi: 10.3748/wjg.v21.i1.311.

42. Li W, Chen G, Yu X, Shi Y, Peng M, Wei J. Accumulation of the mutations in basal core promoter of Hepatitis $B$ virus subgenotype $C 1$ increase the risk of hepatocellular carcinoma in Southern China. International journal of clinical and experimental pathology. 2013;6(6):1076-85. 